1 Emergency Care Research Institute. Training manikins, CPR. Health Derices 1981;10:227-53.

2 Safar P. Cardiopulmonary cerebral resuscitation. Stavanger: Laerdal, 1981:183-203. (Distributed by W B Saunders and available from Laerdal.)

3 American Heart Association. Standards and guidelines for cardiopulmonary resuscitation and emergency cardiac care. F $A M A$ $1980 ; 244: 453-509$.

4 Committee for Evaluation of Sanitary Practices in CPR Training Recommendations for decontaminating manikins used in cardiopulmonary resuscitation training. Resp Care 1984;29:1250-2.

5 Baskett PJF, Lawler PGP, Hudson RBS, Makepeace APW, Cooper C. A resuscitation teaching room in a district general hospital. $\mathrm{BrMed} f$ 1976;i:568-71.

6 Kaye W'. Linhares KC. Breault RV, Norris PA, Stamoulis CC, Khan AH The Mega-Code for training the advanced cardiac life support team. Heart Lung 1981;10:860-5

7 Hon DF. Interactive training in cardiopulmonary resuscitation. Byte 1982; 7(No 6): 108-38.

8 Simons RS. Advanced CPR using a computerised manikin. Fournal of the British Association of Immediate Care 1984;7:41.

Abrahamson $S$, Wallace $P$. Using computer controlled interactive manikins in medical education. Medrcal Teacher 1980;2:25-31

Dr Robert Simmons, FFARACS, FFARCS, is consultant anaesthetist, Royal Free Hospital, London NW3 2QG manikins, such as Resusci or Recording Resusci Anne, and a torso model, such as Ambu-S or Anatomic Anne. For paediatric training a baby or child manikin, or both, should be provided.

For advanced cardiopulmonary resuscitation doctors and nurses in specialised units require access to adult and neonatal intubation trainers and an arrhythmia generator (with or without torso capability).

The burden of teaching has traditionally fallen on anaesthetists, cardiologists, and accident and emergency specialists. The tasks of organisation, training, cleaning, and maintenance of equipment are time consuming if performed properly and merit the appointment of a designated resuscitation training officer, probably with a nursing or paramedical background. Such a person will unify and improve the quality of training and should be affordable within a health district's budget.

Future developments - The use of a microcomputer and video screen to measure performance and display results graphically is already feasible. There is increasing development of sophisticated simulators using computer technology (San Arena, Koken Resim) but these are too costly for most basic cardiopulmonary resuscitation schemes. Hon describes an ingenious computer operated trainer/tester linked to a video disc. ${ }^{7}$ It requires no supervision and has obvious potential for mass training but is very expensive. The market for advanced cardiopulmonary resuscitation trainers is small but demanding and eager for new training techniques. A potential example of a computerised manikin has been described. ${ }^{8}$

In 1967 Sim I, costing some $\$ 100000$, was built as the ultimate in manikin technology. ${ }^{9}$ The next few years will surely see the introduction of affordable and practical simulators at all levels of life support training.

\title{
Epidemiology
}

\section{Haemolytic-uraemic syndrome: clinical experience of an outbreak in the West Midlands}

\author{
C M TAYLOR, R H R WHITE, M H WINTERBORN, B ROWE
}

\begin{abstract}
In 1982-3, 35 children from the West Midlands developed the haemolytic-uraemic syndrome. This was a higher incidence than expected and included an epidemic localised to the Wolverhampton area in July 1983 which comprised 11 cases in two weeks. Twenty three children were treated with dialysis, of whom three died. Six patients developed chronic renal failure, four of them from Wolverhampton. Extrarenal manifestations included neurological sequelae in four, two of whom also developed insulin dependent diabetes mellitus and chronic renal
\end{abstract}

\footnotetext{
Department of Nephrology, The Children's Hospital, Ladywood, Birmingham B16 8ET

C M TAYLOR, MRCP, DCH, consultant paediatrician and nephrologist R H R WHITE, MD, FRCP, professor of paediatric nephrology

M H WINTERBORN, MB, FRCP, consultant paediatrician and nephrologist

Division of Enteric Pathogens, Central Public Health Laboratory, London NW9 5HT

B ROWE, FRCPATH, DTM\&H, director

Correspondence to: Dr Taylor.
}

failure. Cardiomyopathy occurred in one child, who also had chronic renal failure.

The outcome of these 35 patients was not predictable from prognostic criteria derived from previous experience in Britain. This, together with the high prevalence of extrarenal disease and the geographical localisation of the 1983 outbreak, suggested an aetiological agent new to the region. Faeces from 10 patients were examined for verotoxin producing Escherichia coli, and positive strains of serotype $0157 . \mathrm{H} 7$ were found in three patients during the Wolverhampton outbreak.

\section{Introduction}

Since the early descriptions of the haemolytic-uraemic syndrome outbreaks have been reported from several countries but rarely from Britain. ${ }^{12}$ The West Midlands regional paediatric nephrology service draws patients from throughout the West Midlands region as well as parts of central Wales, Gloucestershire, and Leicestershire, representing a total population of nearly 8 million. In the 13 years 1968-81, 32 children with the haemolytic-uraemic syndrome had been admitted, six patients being the greatest number in any one year. In 1982 and 1983 the syndrome was 
diagnosed in a total of 35 children, 11 presenting in an outbreak localised to the Wolverhampton area in July 1983. Though a good outcome would have been anticipated in younger patients with summer onset, "epidemic" haemolytic-uraemic syndrome after a prodrome of diarrhoea, ${ }^{3}$ a high proportion of these children developed chronic renal failure. This outbreak was further distinguished by a high frequency of extrarenal manifestations affecting the central nervous system, pancreas, and heart. This paper draws attention to these clinical features, which, though described in North American reports, are anomalous to previous experience in Britain and may suggest a change in the aetiology of the syndrome in this region. We also report the results of a search for verotoxin producing Escherichia coli in faecal samples.

\section{Present series}

This retrospective review is believed to include all cases of the haemolyticuraemic syndrome in the region. In all patients the diagnostic criteria of renal impairment, microangiopathic haemolytic anaemia, and thrombocytopenia were met.

In 1982, 13 patients (six girls and seven boys) presented, 10 of them during May to October. Most of these children lived in suburban or rural areas (fig 1). In 1983 there were 22 patients-16 girls and six boys; 11 presented during two weeks in July. Ten of these 11 were resident in the Wolverhampton conurbation, the exception being a frequent visitor there.

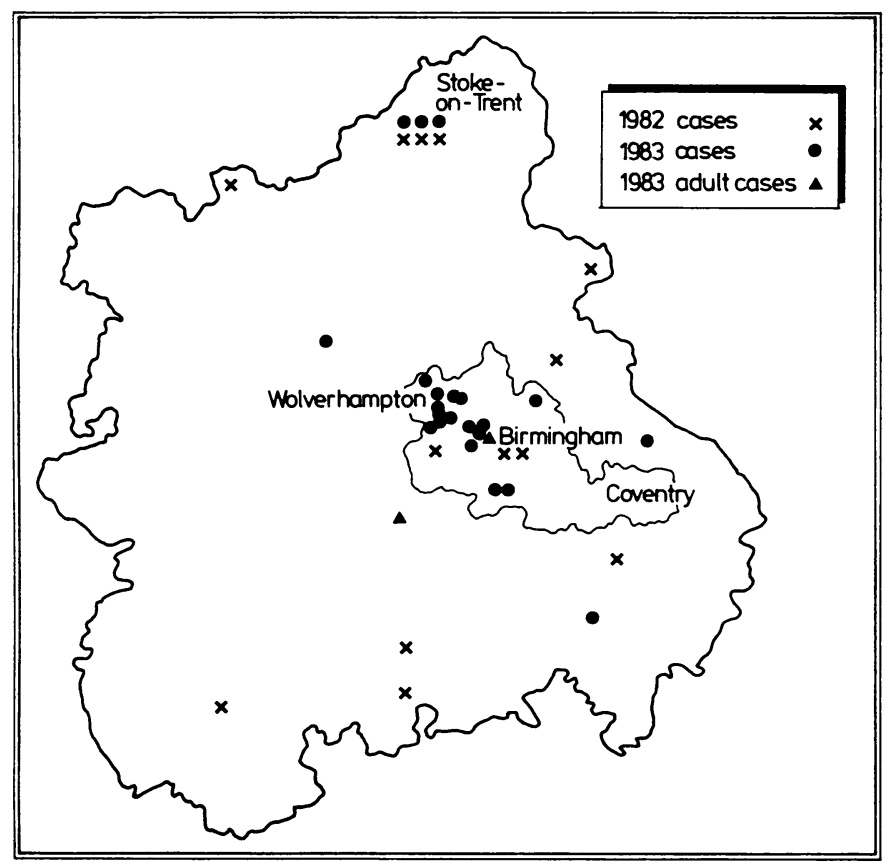

FIG 1-West Midlands region: place of residence of patients.

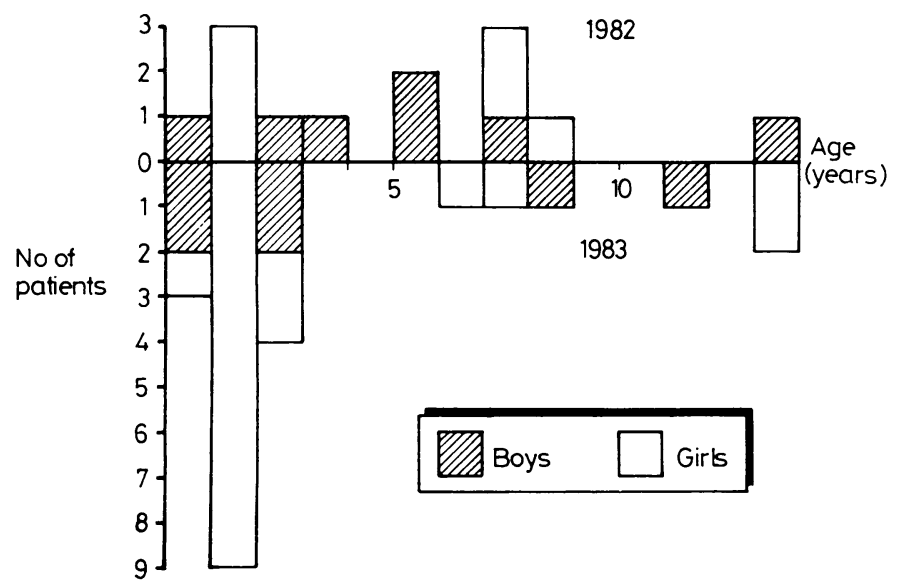

FIG 2-Age of patients at onset of haemolytic-uraemic syndrome.
In the same fortnight two adults from the same urban area (not included in this report) contracted the disease (fig 1). Figure 2 shows the ages of the children at onset, the youngest being 8 months.

Laboratory methods-Haematological and biochemical investigations were performed in the clinical laboratories by standard automated techniques Faecal specimens were obtained as soon as possible and cultured fo Salmonella, Shigella, and Campylobacter spp. Ten faecal specimens were sent to the Central Public Health Laboratory. From each sample $40 E$ coli were examined for verotoxin production ${ }^{4}$ and verotoxin producing strains sero typed according to the internationally accepted scheme. ${ }^{5}$

TABLE I-Prodromal symptoms in 35 children

\begin{tabular}{|c|c|c|c|}
\hline & $\begin{array}{c}\text { No of } \\
\text { patients }\end{array}$ & & $\begin{array}{l}\text { No ofo } \\
\text { patiento }\end{array}$ \\
\hline Diarrhoea & 35 & Jaundice & $3 \stackrel{D}{D}$ \\
\hline Rectal bleeding & 26 & Purpura & 18 \\
\hline $\begin{array}{l}\text { Vomiting } \\
\text { Abdominal pain }\end{array}$ & $\begin{array}{r}21 \\
6\end{array}$ & Seizure & 2 心 \\
\hline
\end{tabular}

\section{Results}

Table I lists the prodromal symptoms in all 35 children. Diarrhoe developed from one to 10 days before admission (mean $5 \cdot 7$ days). A 2 yeaao old boy with abdominal pain underwent a laparotomy for suspected peritonitis, which showed extensive serosal inflammation confined to ther colon but no perforation. Peritoneal swabs proved sterile and no pathogenథ were identified in his stools.

Twelve children had seizures, two before admission. There was a close association between seizure and the timing and magnitude of hypo natraemia. All but one of those with seizures had a plasma sodiun concentration below $126 \mathrm{mmol}(\mathrm{mEq}) / \mathrm{l}$, the exception being a boy with presumed vasculopathy of the central nervous system (case 3; see below) whose sodium concentration remained normal. The lowest recorded plasm? sodium concentration in patients with seizures $(123.3 \mathrm{mmol} / \mathrm{l}$ (SE 1.56$))$ was. significantly lower than those without $\left(129 \cdot 2 \mathrm{mmol} / 1\right.$ (SE 1.35 ); $t=2.85^{\circ}$ $\mathrm{p}<0.01$ ). Hyponatraemia was typically a feature of rehydration wit $(P$ hypotonic saline. Only 10 patients maintained a plasma sodium concentra民 tion above $130 \mathrm{mmol} / \mathrm{l}$ throughout their illness.

In 1982 an adenovirus was isolated from the faeces of one child. In 198 Salmonella typhimurium was isolated from one of the 22 patients and rotaviruses were found in two other children. Of the 10 faecal sampleQ examined for verotoxin producing $E$ coli, positive strains of serotype $0157 . \mathrm{H} 7$ were found in three children. One of these children also excreted $S$ derby. All three children made full recoveries.

In 24 children the plasma creatinine concentration had returned to normat and proteinuria disappeared within four months of onset. A further tw children had marginally raised creatinine concentrations and moderate proteinuria at four months but normal results by one year. Hypertension was not detected in any of these 26 patients with a good outcome during minimum follow up of one year.

Peritoneal dialysis was undertaken in 23 children. Apart from the one. child who died suddenly on the fourth day, all patients who were dialysed foi less than 14 days regained normal renal function, whereas six out of 10 patients who were dialysed for 14 to 52 days progressed to chronic renat failure (fig 3). No patient proceeded directly from acute to end stage renat failure.

Death or long term morbidity was confined to nine patients (table II), five of whom were less than 2 years old at onset. Three children died. One of these (case 1) had stable chronic renal failure for seven months but then developed acute renal failure without recurrence of thrombocytopenia or refi cell fragmentation. The cause of death in case 6 was aspiration pneumonis secondary to spastic quadriplegia. The cardiorespiratory arrest during dialysis in case 7 was not satisfactorily explained. Necropsy showe extensive renal cortical necrosis and intravascular thrombosis confined to the kidney.

Four children sustained neurological damage. In case 2 a right hemiplegia occurred four days after admission. Computed tomography subsequentlu showed cortical atrophy in the territory supplied by the left middle cerebra artery. Central nervous system disease was more diffuse in the othee children. One patient (case 3) developed seizures three hours after admissio 3 without hypertension or electrolyte disturbance. After 11 days of ventilatory support he improved but sustained cortical blindness. Two other patients (cases 6 and 8 ) developed coma, seizures, and spastic quadriplegia followe within a few days by insulin dependent diabetes mellitus. The second of these, who received neither diazoxide nor dexamethasone, remained insulion 
dependent and six months after the original illness was found to have subnormal faecal chymotrypsin activity.

The last patient (case 9) presented with left ventricular failure eight weeks after the onset of the haemolytic-uraemic syndrome, in the absence of electrolyte disturbance or previous hypertension. Antibody to Coxsackie B virus serotypes 1-6 was undetectable. The electrocardiogram showed

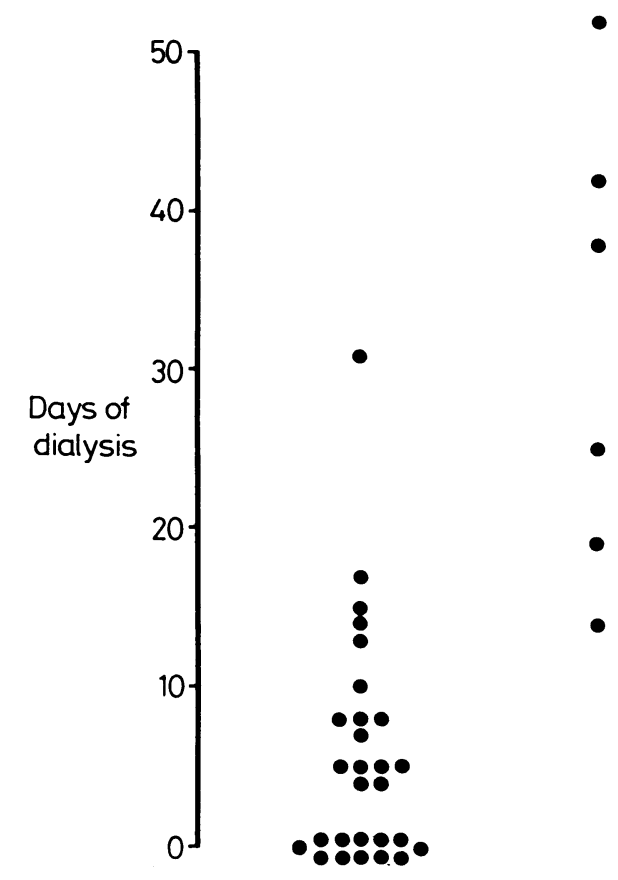

Normal

\section{Chronic renal \\ failure}

FIG 3-Duration of dialysis and follow up renal function (case 7 excluded).
The prognostic score index based on age, sex, season, and prodrome derived from experience in south east England ${ }^{3}$ was applied to our data (fig 4). It predicted a better than $84 \%$ probability of a good outcome for each child who developed chronic renal failure and better than $90 \%$ for those from Wolverhampton; conversely, eight of the 26 children who recovered were given a less than $50 \%$ probability of doing so.

It is unlikely that this inconsistency between two centres in Britain was related to referral practice or treatment, and we consider that the difference in disease pattern was probably related to aetiological factors. A prognostic index which can reliably be applied on admission to hospital is greatly needed in planning a prospective, multicentre, therapeutic trial. The search for such an index in the haemolytic-uraemic syndrome is by no means new, and, though successive attempts ${ }^{378}$ have employed increasingly intricate statistical methods, each has in turn failed when applied to a different patient population, reflecting the heterogeneity of the condition. Other workers have referred to the duration of anuria as an index of severity, but this can be applied only after a variable period in hospital. In modern times this is paralleled by the number of days of dialysis required, and in this respect our findings accord with those of Trompeter et al: that the watershed between good and poor outcomes is at 14 days. ${ }^{3}$

From the earliest descriptions of the haemolytic-uraemic syndrome extrarenal and, in particular, neurological complications have been recorded, ${ }^{9}$ but more emphasis has been given to this in recent North American than European reports. We confirm the observation of Bale et al that the most frequent cerebral disturbance was seizure related to hyponatraemia. ${ }^{10}$ Typically this occurred close to the time of admission and in several instances administration of fluid had been inappropriate. In temperate climates finding hyponatraemia in a child with diarrhoea should suggest the possibility of renal impairment and the need to adjust rehydration appropriately. More serious was fixed neurological deficit (as in cases 2 and 3 ), in which hypertension and hyponatraemia played no part. From our experience both diffuse and focal lesions may occur. The pathogenesis is unknown. Arteriolar microthrombi have been

TABLE II-Details of patients with poor outcome

\begin{tabular}{|c|c|c|c|c|c|c|c|}
\hline \multirow[b]{2}{*}{ Case No } & \multirow[b]{2}{*}{ Date of onset } & \multicolumn{2}{|c|}{ Age } & \multirow[b]{2}{*}{ Sex } & \multirow[b]{2}{*}{ Chronic renal failure } & \multirow[b]{2}{*}{ Died } & \multirow[b]{2}{*}{ Extrarenal manifestations } \\
\hline & & Years & Months & & & & \\
\hline 1 & Feb '82 & 0 & 11 & $M$ & + & + & \\
\hline 2 & July ' 82 & 1 & 4 & $\mathrm{~F}$ & & & Neurological \\
\hline 3 & Sept ' 82 & 5 & 5 & $M$ & & & Neurological \\
\hline 4 & July ' 83 & 1 & 7 & $\mathrm{~F}$ & + & & \\
\hline 5 & July ' 83 & 2 & 8 & $M$ & + & & \\
\hline 6 & July ' 83 & 8 & 7 & $M$ & + & + & Neurological; diabetes mellitus \\
\hline 7 & July ' 83 & 1 & 11 & $\mathrm{~F}$ & & + & Unexplained sudden death \\
\hline 8 & July ' 83 & 2 & 4 & $\mathrm{~F}$ & + & & Neurological; diabetes mellitus \\
\hline 9 & Sept '83 & 1 & 10 & $\mathrm{~F}$ & + & & Cardiomyopathy \\
\hline
\end{tabular}

transient and non-specific $\mathrm{T}$ wave inversion in leads V4 and V5 with ST elevation in V2 and V3 only, but there were echocardiographic findings of ventricular dilatation and hypocontractility, which supported a diagnosis of cardiomyopathy. Serial studies showed return to normal of the size of the left ventricle but ventricular function, though improved, had not become normal by one year of follow up.

\section{Discussion}

The experience during 1982 and 1983 in the West Midlands contains differences from other reports in Britain, ${ }^{1.3}$ though the incidence of death and chronic renal failure was broadly similar to that described by Trompeter et al for 1969-80. ${ }^{3}$ It is widely accepted that the prognosis is more favourable in younger patients presenting in the summer with a prodrome of diarrhoea-the so called "epidemic" form of the disease ${ }^{6}$ - but in the West Midlands cases chronic renal failure was more prevalent in younger patients and was a particular feature of the summer outbreak in Wolverhampton. found in the basal ganglia of some patients at necropsy ${ }^{11}$ but others have reported cerebral oedema and anoxic changes without thrombus formation. ${ }^{1012}$

Insulin dependent diabetes has been described in the haemolyticuraemic syndrome. ${ }^{13}$ it Burns et al reported haemorrhagic necrosis affecting the pancreatic islets, ${ }^{13}$ whereas Andreoli and Bergstein found the $\beta$ cells to be preserved. ${ }^{14}$ Furthermore, Upadhyaya et al detected microthrombi in the pancreatic vasculature of a patient who had died with extensive defects in the central nervous system. ${ }^{11}$ Finding reduced faecal chymotrypsin activity in the surviving diabetic patient in our series suggests exocrine as well as endocrine disease, which would be compatible with an ischaemic insult. Nevertheless, the hypothesis that microvascular occlusion causes the extrarenal disease in the haemolytic-uraemic syndrome, though attractive, fails to explain the apparent predilection of the syndrome for neurological, pancreatic, and myocardial systems. Tissue injury by free radicals containing oxygen may also have a role in the haemolytic-uraemic syndrome, and the recently reviewed suscepti- 
bility of pancreatic $\beta$ cells and cardiac muscle to free radical attack is therefore of interest. ${ }^{\text {is }}$

Verotoxin producing $E$ coli organisms are known to be associated with acute haemorrhagic colitis and were first implicated in the

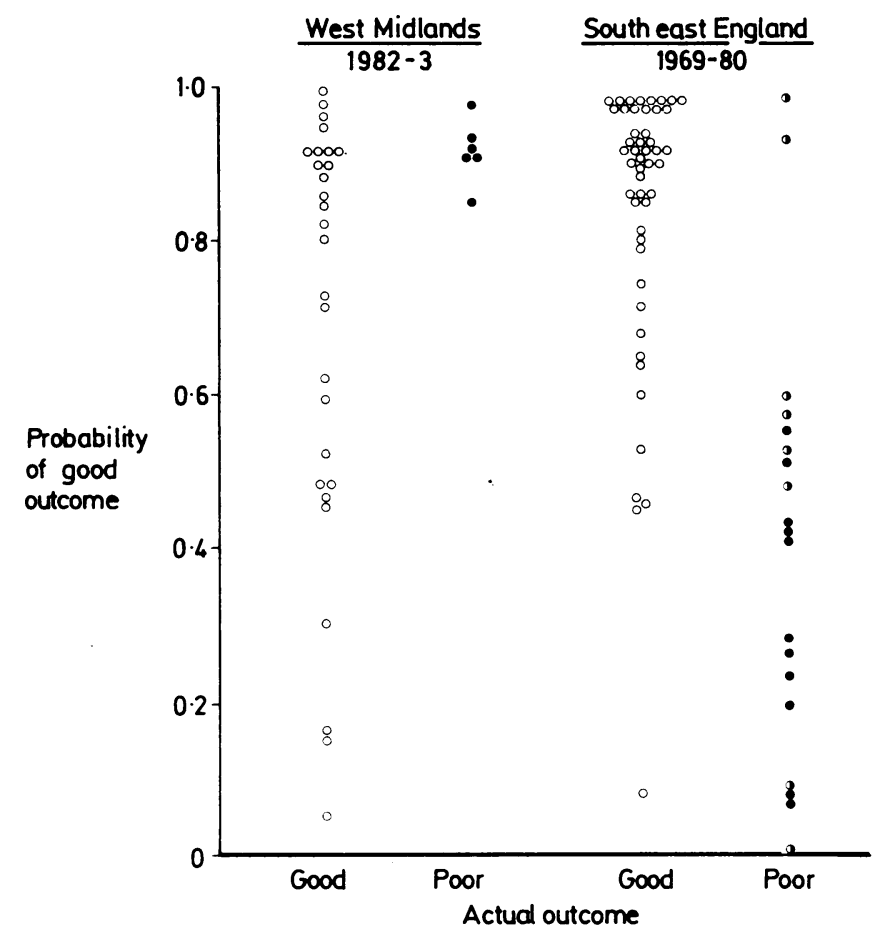

FIG 4-Actual outcome and calculated probability of full recovery. West Midlands patients: $\bigcirc=$ Complete recovery; $=$ Chronic renal failure. South east England patients: $\mathrm{O}=$ Complete recovery; $\boldsymbol{O}=$ Residual nephropathy; $\mathbf{O}=\mathrm{No}$ recovery of renal function.

pathogenesis of the haemolytic-uraemic syndrome by Karmali et al in $1983 .{ }^{16}$ In addition to our three patients, verotoxin producing $E$ coli have been isolated from patients with the haemolytic-uraemic syndrome in other parts of the British Isles (B Rowe, unpublished data). Moreover, Rose et al have shown that plasma incubated with verotoxin is a powerful platelet agonist, whereas verotoxin alone has no aggregatory effect. ${ }^{17}$ Though the clinical characteristics of the Wolverhampton outbreak cannot firmly be attributed to verotoxin producing $E$ coli, the clinical and pathological data described here raise the possibility of a causal relation between verotoxin producing
$E$ coli and the haemolytic-uraemic syndrome. Karmali et al showed that it was necessary to test large numbers of bacterial colonies from each faecal specimen in order to detect verotoxin producing strains $\underline{\underline{T}}$ of $E$ coli. ${ }^{16}$ This is a laborious task, but recently developed 3 deoxyribonucleic acid probes which recognise the genome re- $\varnothing$ sponsible for production of verotoxin allow numerous $E$ coli colonies to be easily tested. This new laboratory tool permits large $\widehat{\Omega}$ numbers of patients to be investigated with valid statistical analysis, $\bar{\Xi}$ and will facilitate a controlled prospective study of the association between verotoxin and the haemolytic-uraemic syndrome.

We thank the following for their help in studying these patients: Dr Faro Raafat, The Children's Hospital, Birmingham; Dr J Newman, East Birmingham Hospital; Dr R G Thompson, Public Health Laboratory Service, New Cross Hospital, Wolverhampton; Dr P R Gully, West Midlands; Dr R S Smith, Stoke on Trent; and Dr R Sunderland, The $\overline{\bar{N}}$ Children's Hospital, Birmingham. We also thank our paediatric colleagues

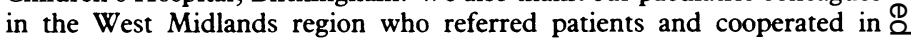
supplying clinical details.

\section{References}

1 McLean MM, Jones $\mathrm{CH}$, Sutherland DA. Haemolytic-uraemic syndrome: report of an outbreak.

Arch Dis Child 1966;41:76-81.
2 Ruthven IS, Fyfe WM. The haemolytic-uraemic syndrome-an epidemic disease? Scott Med 7 . 1968;13:162-5.

3 Trompeter RS, Schwartz R, Chantler C, et al. Haemolytic-uraemic syndrome: an analysis of prognostic features. Arch Dis Child 1983;58:101-5.

4 Scotland SM, Day NP, Rowe B. Production of a cytotoxin affecting vero cells by strains of $\mathrm{C}$ Escherichia coli belonging to traditional enteropathogenic serogroups. FEMS Microbiology $\mp$ Letters 1980;7:15-7

5 Ørskov R, Orskov I. Escherichia coli O:H serotypes isolated from human blood. Acta Palhologica $\vec{G}$ et Microbiologica Scandinavica 1975;83:595-600.

6 Levin M, Barratt TM. Haemolytic-uraemic syndrome. Arch Dis Child 1984:59:397-400.

7 Kaplan BS, Katz J, Krawitz S, Lurie A. An analysis of the results of therapy in 67 cases of the hemolytic-uremic syndrome. I Pediatr 1971;78:420-5.

8 Stuart J, Winterborn MH, White RHR, Flinn RM. Thrombolytic therapy in haemolytic-uraemic syndrome. BrMed f 1974;ii:217-21.

9 Lieberman E. Hemolytic-uremic syndrome. 7 Pediatr 1972:80:1-16.

10 Lalerman E. Hemolytic-uremic syndrome. $f$ Pediatr $1972,80: 1-16$. 政

11 Upadhyaya K, Barwick K, Fishaut M, Kashgarian M, Siegel J. The importance of nonrenal o involvement in hemolytic uremic syndrome. Pediatrics 1980;65:115-20.

12 Rooney JC, Anderson RMcD, Hopkins IJ. Clinical and pathological aspects of central nervous $\square$ system involvement in the haemolytic uraemic syndrome. Aust Paediatr f 1971;7:28-33.

13 Burns JC, Berman ER, Fagre JL, Shikes RH, Lum GM. Pancreatic islet cell necrosis: association with hemolytic-uremic syndrome. F Pediatr 1982;100:582-4.

14 Andreoli SP, Bergstein JM. Development of insulin-dependent diabetes mellitus during the hemolytic-uremic syndrome. $\mathcal{F}$ Pediatr 1982;100:541-5.

15 Anonymous. Metal chelation therapy, oxygen radicals, and human disease [Editorial]. Lancet 1985;i:143-5.

16 Karmali MA, Steele BT, Petric M, Lim C. Sporadic cases of haemolytic uraemic syndrome $\overrightarrow{\vec{A}}$ associated with faecal cytotoxin and cytotoxin producing Escherichia coli in stools. Lancet 3 1983;i:619-20.

17 Rose PE, Armour J, Williams C, Hill FG. Verotoxin and neuraminidase induced platelet aggregating activity: possible role in the pathogenesis of the haemolytic uraemic syndrome. $f$ Clin Pathol 1985;38:438-41.

(Accepted 10 April 1986)
What might be the cause of an apparently fit man in his mid-70s passing little urine during the day and copious amounts at night?

Appropriate tests to eliminate cardiovascular, renal, and endocrine disease are obviously essential but are unlikely to show appreciable abnormality. The effect of drugs, such as alcohol, caffeine, or steroids must also be considered, but the most probable explanation is reversed rhythm of urine output associated with age. Recent studies suggest that the circadian rhythm seen in young people, who normally excrete twice as much urine during the day as during the night, is gradually lost or reversed with advancing years. ${ }^{1}$ Most people over the age of 70 produce the greater part of their urine at night, despite attempts to prevent nocturia by avoiding drinking from late afternoon and high nocturnal plasma osmolalities. ${ }^{2}$ Experiments in young people have shown that the excretory rhythms of water, sodium, potassium, and creatinine can be made to vary independently from each other, so that there is unlikely to be a single cause for their breakdown in the elderly. Variations in the patterns of flow probably result from a combination of changes of endogenous circadian rhythms with age, and deterioration of cardiovascular stretch reflexes which affect the action of salt and water regulating hormones. Changes in physiological responses to posture appear $\tilde{N}$ to be important. Tilt tests in apparently healthy, elderly people have shown functional abnormalities similar to those seen in cardiac failure, and a study $\omega$ in chronically catheterised, female geriatric patients has shown that chair, as opposed to bed, nursing during the day may cause increased excretion of urine at night. ${ }^{3}$ Mild increases in nocturnal urine do not necessarily result in $\overline{\mathscr{D}}$ nocturia, which is more often due to insomnia and detrusor instability, often complicated by prostatic disease in men.-M R BLISS, consultant geriatrician, London.

Kirkland JL, Lye M, Levy DW, Baneriee AK. Patterns of urine flow and electrolyte secretion in healthy elderly people. Br Med f 1983;287:1665-7.

2 Phillips PA, Rolls BJ, Ledingham JGG, et al. Reduced thirst after water deprivation in healthy $\Omega$ elderly men. $N$ Engl J Med 1984;311:753-9.

3 Guite HF, Bliss MR, Mainwaring-Burton JM, Thomas JM, Drury PL. Effect of posture on the circadian rhythm of urine flow and electrolyte excretion in elderly female patients. Clin Sici $1985 ; 69$ (suppl 12). . 